\title{
Metáfora ontológica: a personificação na narrativa mítica e nos processos de formação de palavras Tupí
}

\author{
Ontological metaphor: personification in mythical narratives and \\ in Tupí word formation processes
}

Wany Bernardete de Araujo Sampaio ${ }^{1}$

Joeliza Bezerra Lamarão ${ }^{2}$

\begin{abstract}
Resumo
Este trabalho tem por objetivo a análise de construções metafóricas ontológicas em línguas Tupí, tomando-se por base a teoria cognitiva da metáfora (Lakoff; Johnson 2002). Parte da pesquisa foi realizada no período de 2005 a 2007, com o auxílio do PIBIC/UNIR/CNPq e da Universidade de Porthsmouth (Inglaterra). A abordagem cognitiva de análise linguística se pauta na busca de relações entre a experiência do domínio físico, a natureza conceptual do pensamento e a arquitetura da linguagem; um olhar atento para a linguagem do cotidiano é o bastante para que se perceba o valor e a frequência de expressões metafóricas; além disso, as metáforas estão profundamente relacionadas com os conceitos culturais dos povos, envolvendo fatores culturais, linguísticos, contextuais e cognitivos. No presente estudo, enfoca-se a metáfora ontológica da personificação. São analisadas: (i) duas versões de uma mesma narrativa oral, (ii) sentenças complexas produzidas oralmente; (iii) algumas palavras compostas da língua em foco, demonstrando, no processo de formação dessas palavras, a ocorrência de processos metafóricos, envolvendo a personificação.
\end{abstract}

Palavras-chave: Metáfora Ontológica. Personificação. Línguas Indígenas.

\begin{abstract}
This paper aims the analysis of ontological metaphoric constructions in Tupí languages, taking as basis the cognitive theory of metaphor (Lakoff; Johnson 2002). Part of the research was conducted in the period 2005-2007, with the aid of PIBIC/UNIR/CNPq and Porthsmouth University (England). The cognitive approach of the linguistic analysis is guided in finding relationship between the experience of the physical domain, the conceptual nature of thought and the architecture of the language; a closer look at the language of everyday life is enough to make us realize the value and frequency of metaphorical expressions; furthermore, the metaphors are deeply related with cultural concepts of people, involving cultural, linguistic, contextual and cognitive factors. The present study focuses the ontological metaphor of personification. There are analyzed: (i) two versions of the

${ }^{1}$ Dra. em Linguística; Dra. em Educação Escolar; Pós-Dra. em Linguística Cognitiva. Grupo de Estudos em Culturas, Educação e Linguagens - GECEL/UNIR/CNPq. Fundação Universidade Federal de Rondônia - UNIR.wansamp@gmail.com

${ }^{2}$ Mestranda em Estudos Literários. Grupo de Estudos em Culturas, Educação e Linguagens

- GECEL/UNIR/CNPq. Fundação Universidade Federal de Rondônia - UNIR
\end{abstract}


same oral narrative; (ii) complex sentences orally produced; (iii) some compound words of the language in focus, demonstrating the formation process of these words, the occurrence of metaphorical processes involving personification.

Keywords: Ontological Metaphor. Personification. Indigenous Languages.

\section{Introdução}

Neste trabalho são analisadas construções metafóricas ontológicas nas línguas Tupí, com base na teoria cognitiva da metáfora (Lakoff e Johnson 2002). A abordagem cognitiva de análise linguística se pauta na busca de relações entre a experiência do domínio físico, a natureza conceptual do pensamento e a arquitetura da linguagem; um olhar atento para a linguagem do cotidiano é o bastante para que se perceba o valor e a frequência de expressões metafóricas; além disso, as metáforas estão profundamente relacionadas com os conceitos culturais dos povos, envolvendo fatores culturais, linguísticos, contextuais e cognitivos.

O estudo aqui apresentado se baseia em dados oriundos do Projeto de Pesquisa "Espaço, Movimento e Metáfora em Amondáwa", desenvolvido pelo Grupo de Estudos em Culturas, Educação e Linguagens - GECEL/UNIR/ $\mathrm{CNPq}$, no período compreendido entre os anos de 2003 a $2008^{3}$. O projeto foi realizado em parceria com os professores indígenas da escola Amondáwa, na aldeia Amondáwa, Posto Indígena Trincheira, Área Indígena Uru-eu-uau-uau, estado de Rondônia ${ }^{4}$.

Com o intuito de obter dados linguísticos o mais naturalmente possível e que não se constituíssem de simples respostas a questionários, os pesquisadores do GECEL elaboraram protocolos de campo e vários outros instrumentos, como jogos e maquetes, todos baseados na cultura dos indígenas e na arquitetura espacial da aldeia e de seu entorno. Tais instrumentos contribuíram para uma produção linguística menos artificial, pelo fato de que os indígenas colaboradores constituíram textos narrativos, textos descritivos de ações de movimento, textos opinativos, todos em sua língua materna; tais textos foram transcritos e

\footnotetext{
${ }^{3}$ Os dados utilizados se referem ao período de 2005 a 2007 e contou com auxílios do PIBIC/UNIR/CNPq, da Universidade de Porthsmouth - UoP/England e da União Europeia, como subprojeto do programa internacional "What it means to be human". Participaram do projeto neste período, juntamente com as pesquisadoras autoras, as alunas de graduação Arlete Vrena Rodrigues, Cristiane de Almeida Anastassioy e Janaína Kelly Leite Chaves; os pesquisadores associados: Chris Sinha Joerg Zinken e Vera da Silva Sinha - UoP/England; os professores Arikan e Mande'i Amondawa; várias crianças, jovens e adultos Amondáwa colaboraram imensamente com o trabalho.

${ }^{4}$ Os Amondáwa são falantes de língua Tupi, Família Tupi Guarani, Grupo Tupi Kawahib. Seus primeiros contatos com a sociedade não índia datam de 1986.
} 
glossados com a ajuda dos professores e outros jovens indígenas, utilizando-se a ferramenta ELAN 5 .

No texto que ora apresentamos, focamos nossos estudos nas construções metafóricas, na língua Amondáwa, as quais refletem o uso da metáfora ontológica da personificação, em que as entidades não humanas são concebidas como pessoas, o que nos permite "dar sentido a fenômenos do mundo em termos humanos". (Lakoff; Johnson 2002).

O presente texto está organizado em duas partes: na primeira, apresentamos uma breve discussão sobre o pensamento metafórico; na segunda, analisamos: a) uma versão de uma mesma narrativa oral, contada por dois distintos narradores; b) algumas sentenças complexas; c) algumas palavras compostas da língua em foco, demonstrando, no processo de formação dessas palavras, a ocorrência de processos metafóricos, envolvendo a personificação e outras (prováveis e possíveis) metáforas ontológicas. Em seguida, tecemos algumas considerações acerca da análise realizada.

\section{0 pensamento metafórico}

De acordo com Lakoff (1987), nós, seres humanos, temos o poder do pensamento abstrato em virtude de nossa capacidade de conceituar. Tal capacidade compreende, segundo o autor, três habilidades:

a) A habilidade para formar estruturas simbólicas correlatas a estruturas pré-conceituais na nossa experiência cotidiana. Tais estruturas simbólicas compreendem conceitos de nível básico e conceitos imagético-esquemáticos;

b) A habilidade para projetar metaforicamente estruturas no domínio físico para estruturas em domínios abstratos, regulada por outras correlações estruturais entre os domínios físico e abstrato. Isto explica nossa capacidade de pensar sobre domínios abstratos tais como quantidade e intenções.

c) A habilidade para formar conceitos complexos e categorias gerais usando esquemas imagéticos como dispositivos estruturantes. Isto nos permite construir estruturas para eventos complexos e taxonomias com categorias superordenadas e subordinadas. (Lakoff 1987:280281, tradução das autoras)

Todos os seres humanos possuem capacidades cognitivas conceituais; suas concepções e visões de mundo são organizadas e expressas através da língua, sendo a metaforização um dos principais instrumentos para a construção da

\footnotetext{
${ }^{5}$ O ELAN é uma ferramenta para a criação de anotações complexas em recursos de áudio e vídeo. Ver: http://tla.mpi.nl/tools/tla-tools/elan/. Instituto Max Planck de Psicolinguística; Arquivo de idiomas, Nijmegen, Holanda.
} 
significação, para a atribuição de sentidos. Lakoff (1997:302) afirma, ainda, que "a significação envolve não apenas estruturas mentais, mas a estruturação da experiência em si mesma".

Vários estudos mais recentes em linguística cognitiva consideram que a construção da significação é um processo bastante dinâmico: citem-se, por exemplo, os estudos de Kövecses (2005, 2006, 2009), Croft e Cruse (2004); estes dois últimos estudiosos afirmam que:

[...] as palavras realmente não têm significado, nem as sentenças têm significados: os significados são algo que construímos, usando propriedades dos elementos linguísticos, como informações parciais, ao lado de conhecimentos não linguísticos, informações disponíveis no contexto, conhecimentos e conjecturas, considerando o estado de espírito dos ouvintes, entre outros. (Croft e Cruse 2004:98, tradução das autoras).

Esta afirmativa nos permite inferir que, na construção da significação, os contextos cultural e situacional desempenham papéis fundamentais.

Com referência aos modelos cognitivos, Lakoff (1987) explica que estes tem sua significação fundamental diretamente derivada de suas habilidades de correspondência com estruturas pré-conceituais. Entretanto, nos domínios onde a estrutura pré-conceitual não é claramente discernível para nossa experiência, nós importamos tais estruturas através da metáfora. Diz o autor:

A metáfora nos provê um meio para a compreensão de domínios que não possuem uma estrutura pré-conceitual própria. A compreensão da experiência via metáfora é um dos grandes triunfos imaginativos da mente humana. Muito do pensamento racional envolve o uso de modelos metafóricos. Uma explicação adequada da racionalidade deve considerar o uso da imaginação e muito da imaginação consiste no pensamento metafórico. [...] A ideia da capacidade de conceituar é central para a abordagem experimentalista. Uma capacidade que toma estruturas pré-conceituais da experiência como estímulos e os usa para motivar conceitos. Uma capacidade que explica: (a) como nós adquirimos nossos conceitos; (b) como os conceitos estão vinculados a estruturas pré-conceituais, (c) por que os conceitos têm as propriedades peculiares que têm; (d) como nós podemos entender nossos conceitos e como nós podemos vir a entender, mesmo em sistemas conceituais muito diferentes. (Lakoff 1997:302- tradução das autoras)

Para Lakoff e Johnson (2002), a metáfora não é apenas um recurso da imaginação poética e/ou um ornamento retórico: "a metáfora está infiltrada na vida cotidiana, não somente na linguagem, mas também no pensamento e na ação. Faz parte de nosso sistema conceptual que é metaforicamente estruturado e definido" (Lakoff e Johnson 2002:45). 
Consoante à abordagem teórica aqui adotada, resumidamente, os conceitos metafóricos podem ser:

a) Estruturais: casos em que um conceito é estruturado metaforicamente em termos de outro conceito (pelo menos parcialmente); por exemplo: se tomamos o conceito "discussão é guerra", podemos abstrair daí o que fazemos quando discutimos, bem como a maneira pela qual compreendemos o que fazemos.

b) Orientacionais: casos em que um conceito organiza todo um sistema de conceitos em relação a um outro conceito. A maior parte está relacionada à orientação espacial (para cima/para baixo; para dentro/para fora, etc.); por exemplo, a expressão linguística "Hoje eu estou para cima!" repousa no conceito "feliz é para cima".

c) Ontológicos: as metáforas ontológicas se baseiam na nossa experiência com objetos ou substâncias físicas (especialmente com nosso corpo), em função das quais lidamos com noções abstratas, nas formas de conceber eventos, atividades, emoções, ideias, etc. como entidades e substâncias. As metáforas ontológicas nos permitem uma grande variedade de propósitos, tais como: referir-se; quantificar; identificar aspectos; identificar causas; traçar objetivos e motivar ações, entre tantos outros. Muitas vezes, nem percebemos tais tipos de construções como metafóricas, pois elas estão extremamente presentes na nossa vida cotidiana.

Dentre as metáforas ontológicas encontra-se a personificação, objeto deste trabalho.

\subsection{A personificação}

De acordo com Dubois et al. (1993:466),

A personificação é uma figura de retórica que consiste em fazer de um ser inanimado ou de um ser abstrato, puramente ideal, uma pessoa real, dotada de sentimento e de vida. A personificação pode ocorrer por metonímia: Argos vos estende os braços e Esparta vos chama (Racine, Phêdre); por sinédoque: Os vencedores falaram. A escravidão em silêncio obedece à sua voz, na cidade imensa (Voltaire, L'Orphelin de la Chine); por metáfora: Sobre as asas do Tempo, a Tristeza se esvai.

Não vamos adotar, em nossa discussão, o conceito de personificação como figura de retórica, no sentido de ciência nem de arte do bem falar, como é costumeiro. Mas é verdade que a personificação pode ocorrer através de diversos processos linguísticos (nominados por metonímia, metáfora, 
sinédoque, catacrese, entre outros); a personificação cobre uma imensa gama de construções metafóricas. Vamos olhar, portanto, a personificação na linguagem cotidiana, tendo-a como uma metáfora ontológica em que "os objetos físicos são concebidos como pessoas" (Lakoff e Johnson 2002:87).

Ao utilizarmos a personificação, estamos atribuindo a seres e entidades não humanas, (animados e/ou inanimados) qualidades humanas; na realidade, não nos reportamos a seres humanos; a personificação cobre uma variedade enorme de metáforas e cada metáfora de personificação seleciona diferentes aspectos de uma pessoa, ou modos diferentes pelo qual se considera a pessoa. O que essas metáforas têm em comum, segundo Lakoff e Johnson (2002), "é o fato de serem extensões de metáforas ontológicas, permitindo-nos dar sentido a fenômenos do mundo em termos humanos, como base de nossas próprias motivações, objetivos, ações e características" (Lakoff e Johnson 2002:87-88).

Assim, baseando-nos nesses pressupostos, buscamos olhar construções metafóricas ontológicas de personificação na língua Amondáwa-e que apontem para conceitos metafóricos - considerando que todos os seres humanos possuem a capacidade de conceituar, o que nos dá o poder do pensamento abstrato.

\section{Análise}

\subsection{Narrativas}

Nesta seção, analisamos duas versões de uma mesma narrativa contada por duas crianças Amondáwa através da técnica de indução, a partir de um jogo de imagens (narrativa visual) representativo de uma narrativa mítica da cultura Amondáwa. A edição da narrativa visual teve como base as narrativas orais do mito A origem da lua (Sampaio; Silva; Miotello 2004), anteriormente contadas por dois distintos narradores, falantes da mesma língua, adultos e autorizados: Tari e Tangip Amondawa.

Por narrador autorizado referimo-nos àquele que cultural e socialmente possui o poder de proferir as narrativas míticas e históricas nas sociedades ágrafas. Vale lembrar, aqui, as palavras de Benjamin (1985):

A narrativa, que durante tanto tempo floresceu no meio de artesãos no campo, no mar e na cidade -, é ela própria, num certo sentido, uma forma artesanal de comunicação. Ela não está interessada em transmitir o 'puro em si' da coisa narrada como uma informação ou um relatório. Ela mergulha a coisa na vida do narrador para em seguida retirá-la dele. Assim se imprime na narrativa a marca do narrador, como a mão do oleiro na argila do vaso.

Assim, cada narrador autorizado imprimiu em sua narrativa suas próprias marcas, o seu estilo, o seu jeito especial de narrar, o que demonstra o seu jeito especial e subjetivo. Por seu turno, as crianças, ao se colocarem na condição de 
leitor, diante do jogo de sequência de imagens, também se tornaram narradores; ao recontarem o mito, as crianças, ao seu modo, atribuíram um novo sentido ao texto imagético a elas apresentado, fazendo a sua própria leitura e construindo, a partir daí, o seu próprio texto verbal.

A seguir, transcrevemos as duas versões das narrativas que basearam o trabalho de produção do jogo de imagens (narrativa visual):

Versão 1: A Origem da Lua (Narrador: Tari Amondawa 1998)

A lua era uma mulher que ficou brava e foi ficar no céu (não sei se era assim. Minha vó contou muito essa história; minha mãe contou muito também) A mulher ficou com raiva porque o namorado dela arrumou outra namorada. Ela ficou brava e disse:

- Ah! Eu não fico aqui mais não. Eu vou morar no céu.

Aí foi embora, subiu no pau lá em cima, muito alto. O pessoal chamou ela de volta e ela dizia:

- Ah! Eu vou embora daqui mesmo. Eu vou embora.

Ai ficou no céu, ficou direto lá, virando lua.

Primeiro não tinha nada escuro. Ai bicho bravo andava muito aqui. Ai Tupana ngá mudou: bicho bravo tem que dormir, vai entrar no buraco escondido de manhã cedo.

Índio vai caçar no mato de manhã cedo. Quando fica escuro, aí dá pra dormir, porque antigamente não tinha escuro e bicho bravo ficava andando de dia: jararaca, aranha, tucandeira, tudo andava de dia. Agora aranha se esconde e dorme de manhã e de noite vai andar de novo.

Índio ficava conversando no mato, direto, só dormia meio dia bem pouquinho e depois voltava pra caçar de novo. Não tinha escuro pra dormir nem nada. Aí Tupana ngá mudou pra escuro. Manda kuará ir embora, aí depois vem jahya, a lua, e fica escuro. (Agora não perco mais não. Agora eu sei o que fazer). Tupana nga é aquele lá em cima (na tua língua é Deus, né?).

Kuará vem, ele não mudou não, agora jahya mudou.

- Não vem de noite, né? Eu vou estar funcionando de noite. Você vem meio dia, kuará; amanhã você, kuará. De noite está funcionando eu. Assim falou jahya.

Por isso de noite está funcionando jahya.

Versão 2: A lua (Narrador: Tangip Amondawa, 1997)

Acho que era uma índia que virou lua, porque falaram mal dela. Todo mundo xingou ela. Aí ele foi, subiu no pau... Ela queria ficar no céu ... Depois 
ela voltou de novo com nosso povo. Ela voltou e ficou lá outra vez... Ela quis ficar lá no céu pra clarear tudo aqui embaixo, porque acho que antigamente num tinha nada claro assim de noite, né?

Com base nessas duas versões do mito, nós, pesquisadores, elaboramos uma narrativa visual (jogo de sequência de imagens) ${ }^{6}$; saliente-se que o objetivo do trabalho com narrativas visuais não era o de que os participantes recontassem o mito, mas o de estimular os falantes a produzirem narrativas orais, em língua nativa, de forma bem natural, partindo de algo que (imaginávamos) eles (re)conheceriam por ser parte do seu mundo cultural. Assim, as crianças, embora ainda não acostumadas com essa prática pedagógica, conseguiram produzir sequências sentenciais coerentes com as sequências de imagens (não necessariamente na mesma ordem) e utilizaram conectores interfrásticos marcadores de sequência de temporalidade característicos de textos narrativos.

A seguir, apresentamos a narrativa visual trabalhada com as crianças:

História da Lua - Sequência narrativa visual

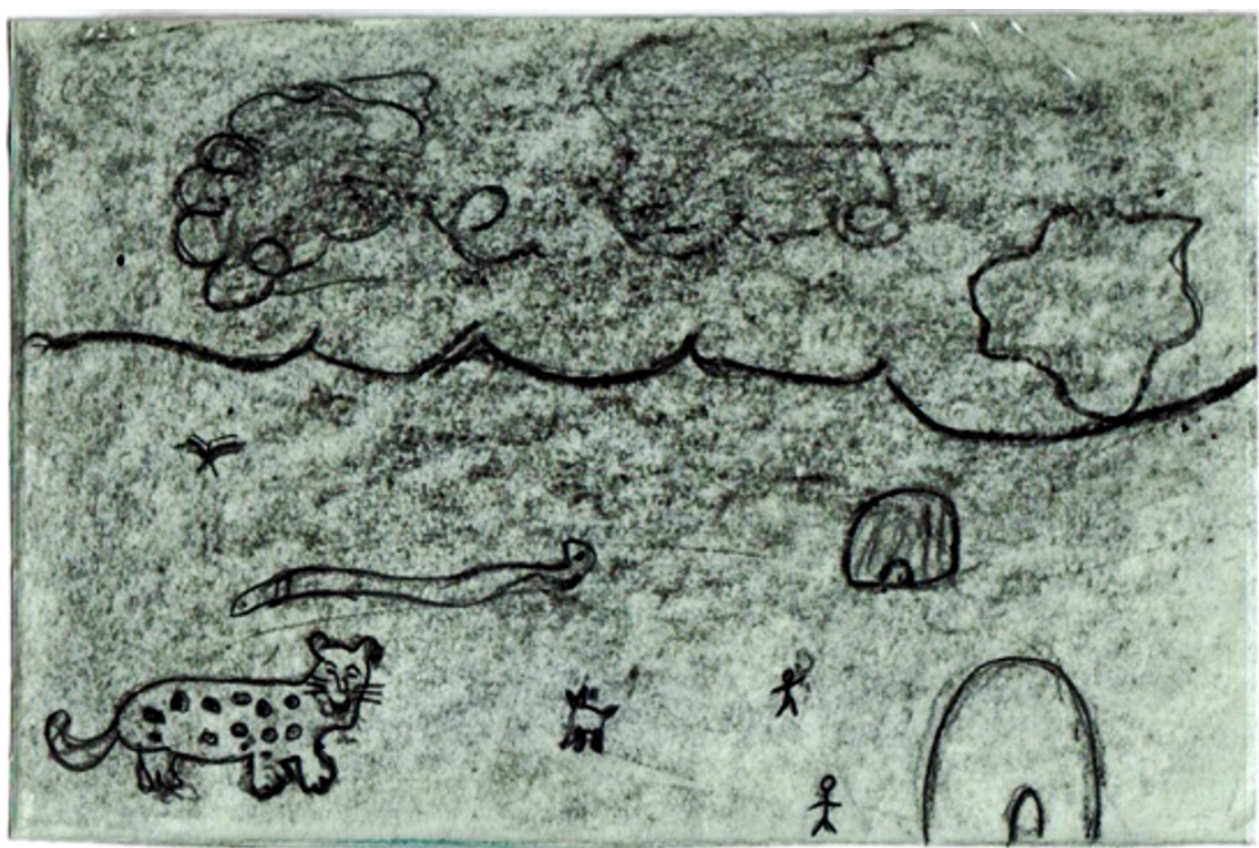

${ }^{6}$ O trabalho de campo com narrativa visual foi realizado em 2005, por Vera da Silva Sinha e Wany Sampaio. Dele participaram muitos indígenas: crianças, mulheres, jovens, adultos. Selecionamos apenas as narrativas produzidas por duas crianças: Juvitai e Mboroap Amondáwa. Os dados aqui apresentados foram retirados de SAMPAIO e CHAVES (2006). 

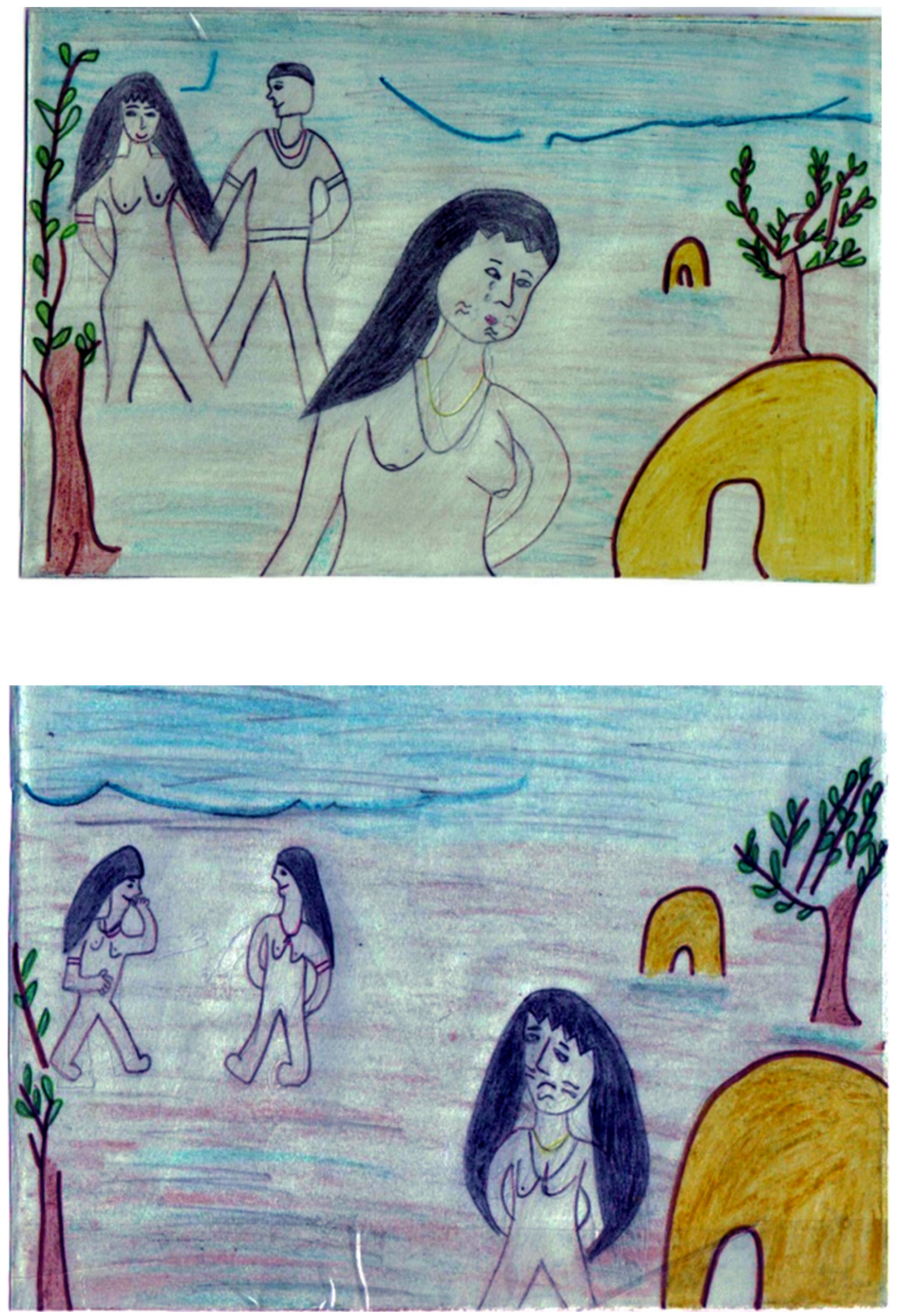

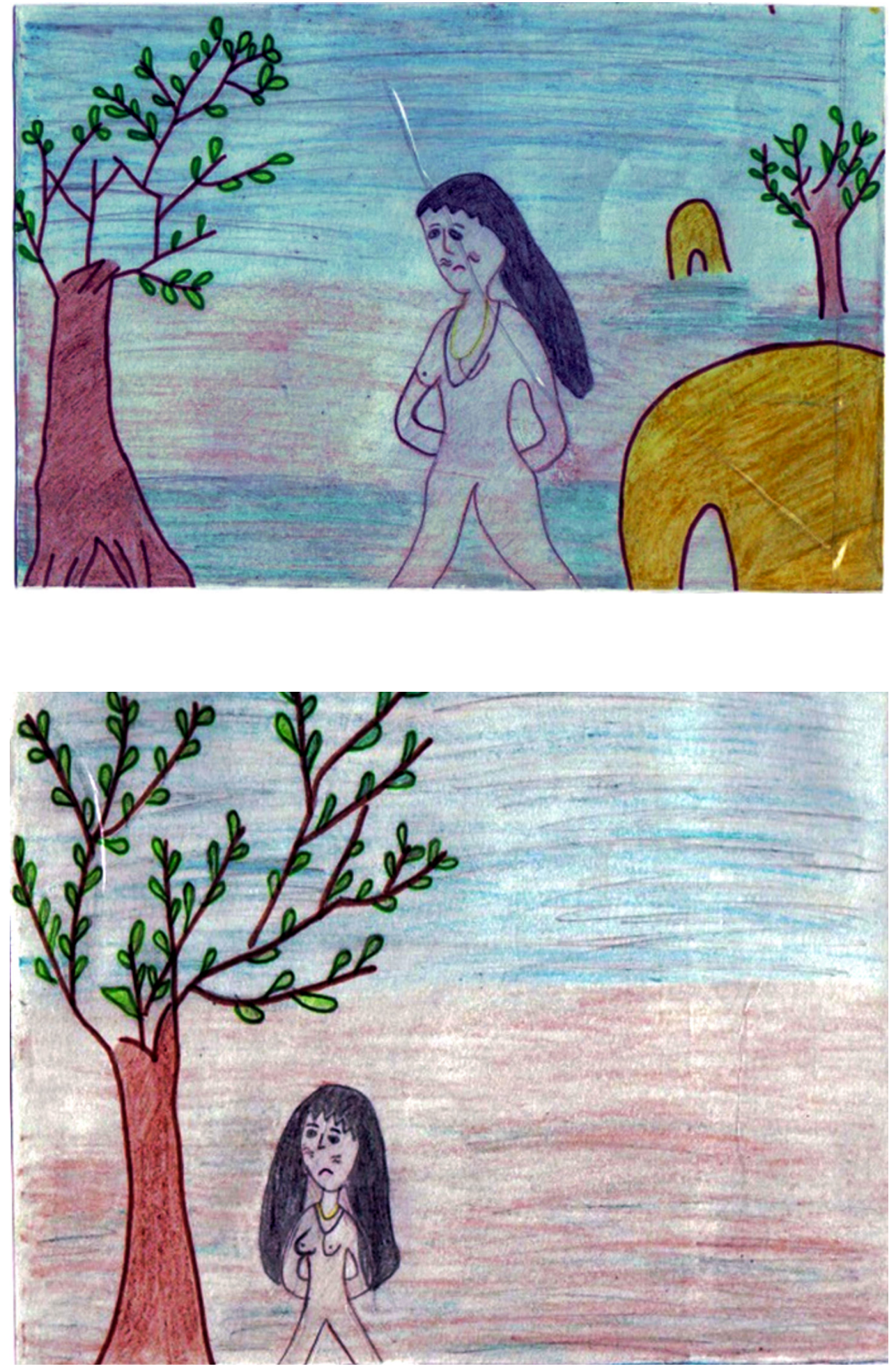

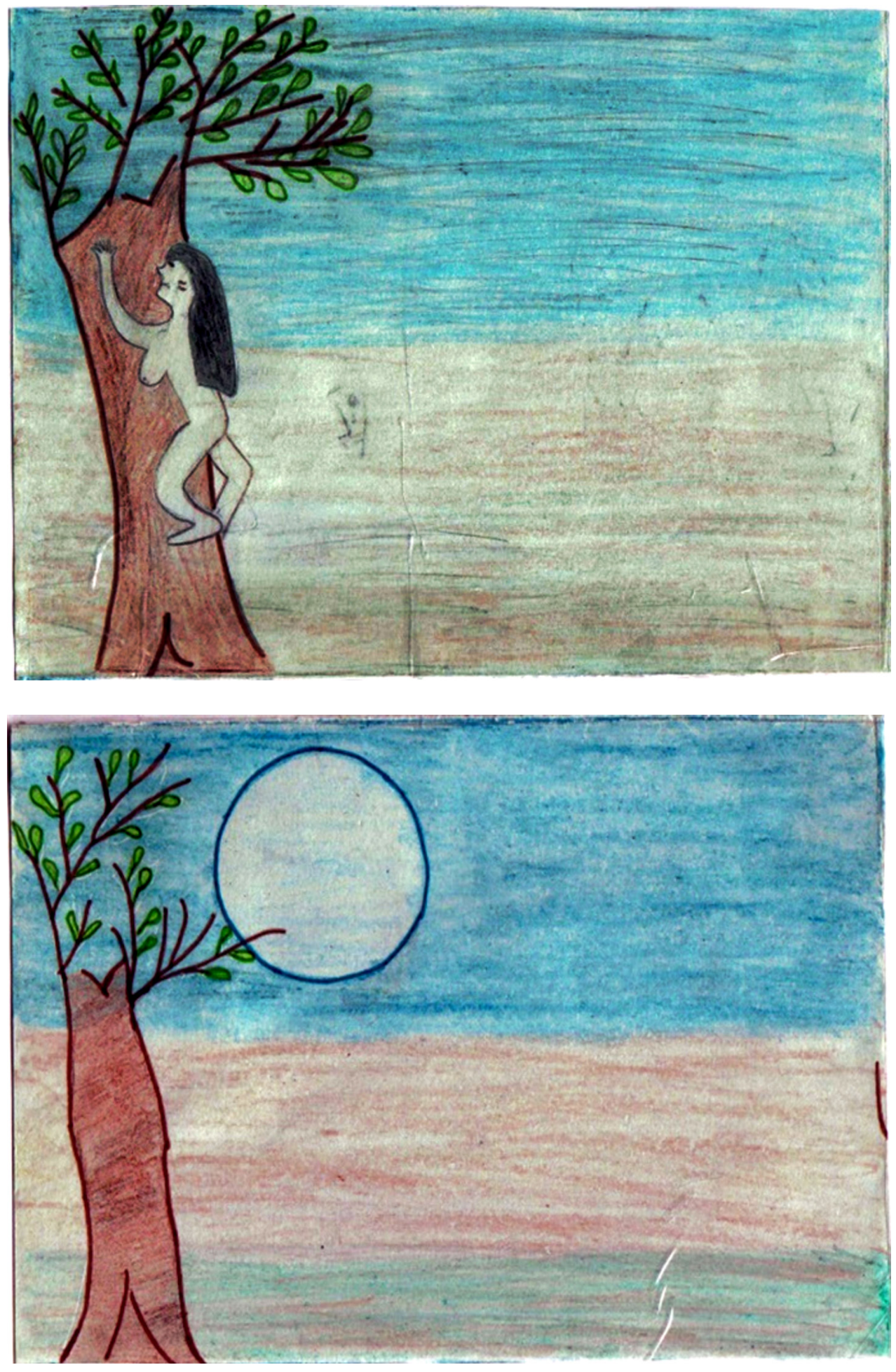

Volume 7, Número 1, Julho de 2015123 


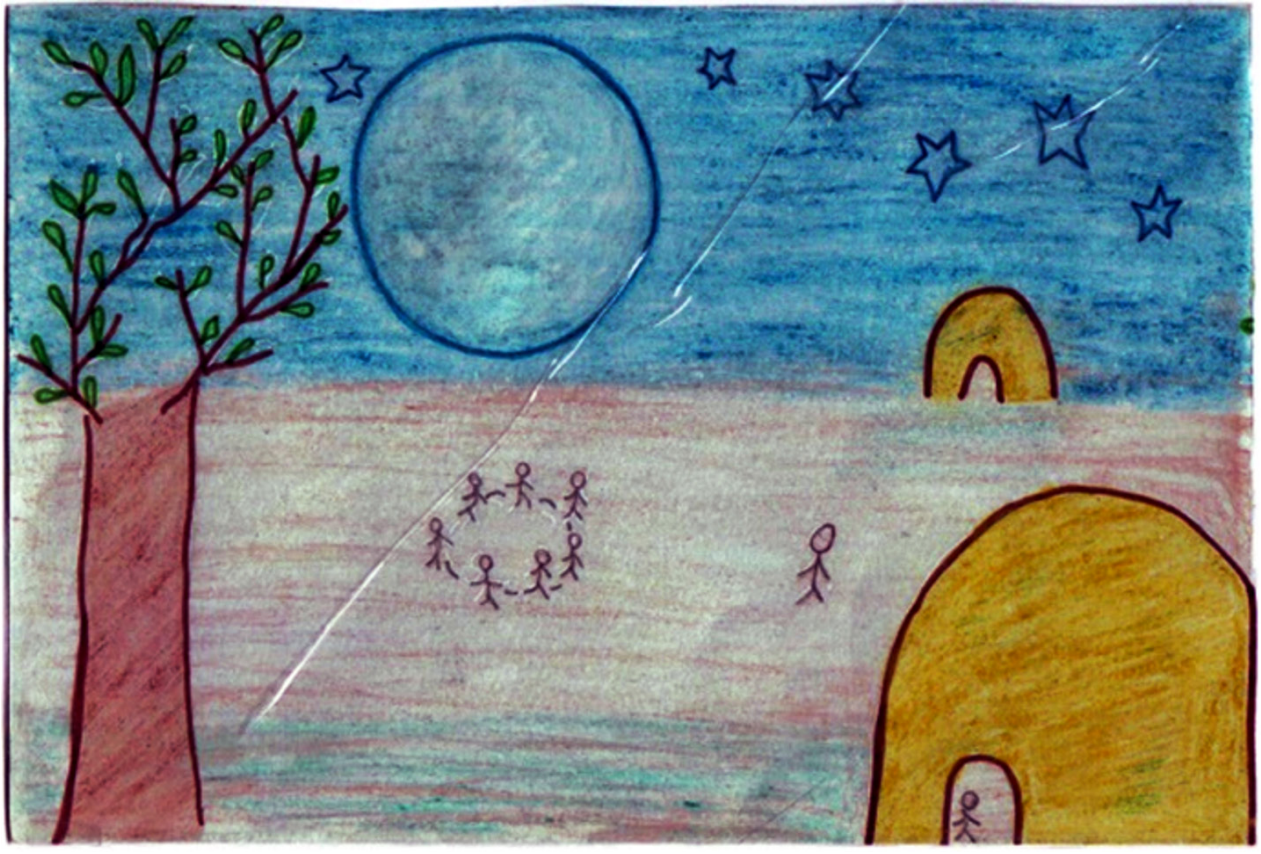

Vejamos, a seguir o texto produzido oralmente pela criança Participante 1:

Participante 1: Juvitai Amondawa (2005)

Jatata'ia hea awape ipieka ..... ngã repieka

Ngã hemi ngã hua ngã repiaka maloka veia wi

Jahya apiek ngã ngã repiaka

Jatata'ia ywa pe gare epiaka

Molakaveia penga ame pe'i jiaquarabua ame

Ara nga hemi jyhya ngarepieka Jatata'ia awape ngarepieka

Malokawi nga hemi hua

Jahya andyremo y'yia pyri

Garare ngã epieki ama ajuwai ura urumo nga ame

Iputunahuape jawara ako ñãpytera pe

Mboja tambem akymaemi 'ua ipieka mamangaia ako ngapiri

Malokaveiawi ngaemi ua

Heahã awerekoihea heahã

Ara hea aiapykaihea meme

Awowen hea ama urare o'am maloka veia aramo

Ara hea iapykawo hea meme ara hea taijupin i'i hea 'ama

Jahya ama

Ara ura i'ame ura aramo maloca veia aramo

Ara hea awowen hea 'ama tajupin hea

Virawo jahya aramo jowo 


\section{Tradução:}

A estrela está olhando para as pessoas... eles estão olhando (para a estrela). Eles saíram da maloca velha para olhar (a estrela)

A lua olhou para eles, eles olharam...

Ele olha para a estrela na árvore

Um está em pé perto da maloca velha, olhando, zangada (de cara feia).

Então ele saiu, olhou a lua

A estrela (olha) para as pessoas... eles olham (para a estrela)

Ele sai da maloca velha

A lua brilha junto da água

Eles estão em pé, do outro lado, olhando, em pé, debaixo da casa

A noite veio, a onça está

A cobra também saiu e veio olhar, a abelha está pertinho dela.

Ela saiu da maloca velha e veio

Ela mesma que está aqui

Então ela riu mesmo... ela, os dois

Ela, que estava zangada, ficou em pé em cima da casa. Estava em pé acima da maloca velha

Então ela mesma rindo, ela, os dois

Então ela subiu mesmo, muito... Ela ficou em pé

A lua ficou em pé

Então ela ficou em pé por cima da casa, por cima da maloca velha

Então, ela, a que estava zangada, ficou em pé, subiu

e virou lua, lá em cima (porque ela mesma estava querendo virar a lua)

Deste texto, pudemos extrair as seguintes metáforas ontológicas de Personificação:

(1) Jatata'ia hea awape ipieka ..... ngã repieka ....

Jatata'i-a hea awa pe i-piek-a ngã r-epiek-a

Estrela-NOM ela pessoas em 3s-olhar-GER eles REL-olhar-GER

A estrela está olhando para as pessoas ... eles estão olhando (para a estrela)

(2) Iputuna hua pe jawara ako ñapytera pe

Ipytun-a hu-a pe jawar-a a-ko ñapyter-a pe

escuro-NOM vir-GER em onça-NOM 3-estar.em.mov. em

A noite veio em...., a onça está ....

(3) Jahya 'ama

Jahy-a 'am-a

Lua-NOM estar em pé-GER

A lua ficou em pé 
Nas construções (1), (2) e (3), há claras ocorrências da metáfora ontológica de personificação: em (1) tem-se a personificação da estrela (jatata'ia), dado que a ela é atribuída a faculdade humana do olhar; em (2), tem-se a personificação da noite (ipytuna), a quem é atribuída a faculdade humana do andar, do vir, do movimentar-se no espaço; em (3), tem-se a personificação da lua (jahya), à qual se atribui a ação de ficar em pé.

É possível, assim, supormos que as construções (1) e (3) têm aporte em uma metáfora conceitual do tipo "Corpos celestes são pessoas". Não podemos olvidar que, de acordo com o mito, a lua era uma jovem, portanto uma pessoa, o que, de certa forma, justifica a projeção do conhecimento da realidade cultural na realidade mítica em forma de personificação da lua, assim como casos da personificação do sol. E, até onde sabemos, as estrelas e a noite, assim como a divisão do dia e da noite, na mitologia desses indígenas, são criações de Tupana ngá,

Para a construção (2), podemos hipotetizar, como metáfora conceitual, que “Tempo é movimento". Dizemos hipotetizar por ser esta uma proposição nossa, dado que "não há uma palavra para tempo em Amondáwa; não há palavras para semana, meses e anos e nem nomes para festas referenciadas no tempo; há nomes para as estações e partes de estações, para o dia e noite e partes do dia e da noite, há dêiticos temporais e termos adverbiais temporais". (Sampaio et al. 2010). Isto significa que, embora lexicalmente não tenhamos uma palavra para TEMPO, nos termos abstratos em que o compreendemos, a língua Amondáwa não é uma língua "sem tempo". A determinação da regra central do movimento metafórico e a construção da experiência temporal se dão a partir da perspectiva do falante. Seus intervalos de tempo possuem fronteiras bem definidas e constituídas por eventos em si mesmos, como, por exemplo, o nascer do sol, o cair da chuva, o chegar da noite, etc.

Vejamos, a seguir o texto produzido oralmente pela criança Participante 2:

Participante 2: Mboroap Amondawa (2005)

Awowehea i'am yvyra ipieka

Awowen hea 'ama yra epieka

Pytunuhua pyri hea hoi 'am

Ara hea ñoroi nga repieka maloca pyri agora la em cima

Ara nga hemi ipieka jawara mboja powe

Ara hea 'am taijupin ywyrare jowo

Jahya ipoki

Ara hea koawi

Ara hea pe'i hea hemi ua maloca veia wi

Estrela aindy ngã aramo 


\section{Tradução:}

Ela estava zangada, olhando, em pé perto da árvore

Ela estava zangada, em pé, na casa, olhando.

A noite veio para perto e ela foi em pé.

Então ficou olhando zangada perto da maloca velha... agora lá em cima

Então ela saiu, olhando, a onça com a cobra.

Então ela ficou em pé, subiu mesmo na árvore (ela estava mesmo querendo subir na árvore).

A lua espocou

Então ela dançou

Então uma mulher saiu e veio da maloca velha

A estrela brilha por cima deles.

Nesse texto, encontramos uma ocorrência de personificação em:

(4) Pytuna hua pyri hea hoi 'am

ipytun-a hu-a pyri hea hoi 'am
escuro-nom vir-ger perto ela ir estar em pé
A noite veio (para) perto. Ela foi ficar em pé

A noite veio (para) perto. Ela foi ficar em pé

Na construção (4) da narrativa da Participante 2, repete-se a ocorrência de personificação demonstrada na construção (2) da narrativa produzida pela Participante 1: a personificação da noite (ipytuna), a quem é atribuída a faculdade humana do andar, do vir, do movimentar-se no espaço.

Segundo Lakoff e Johnson (2002:71), "os valores fundamentais de uma cultura serão coerentes com a estrutura metafórica dos conceitos fundamentais dessa cultura". Compreendemos, assim, que a ocorrência da seleção do mesmo aspecto humano para personificação da noite na narrativa de cada criança revela a consistência e a coerência da cultura com a metáfora conceitual, já que a noção de temporalidade é culturalmente definida pelos eventos em si mesmos, como já dissemos antes.

\subsection{Sentenças complexas}

Nesta seção, analisamos algumas sentenças complexas produzidas oralmente através do Jogo do Espaço realizado a partir de uma maquete da aldeia, utilizando elementos lá existentes: casas de famílias, farmácia, escola, casa de farinha, casa do chefe de posto da FUNAI, animais, árvores, carros, etc. ${ }^{7}$ Desse trabalho, resultou um número bastante significativo de construções

\footnotetext{
${ }^{7}$ O trabalho de campo com o Jogo do Espaço foi realizado em 2005, por Vera da Silva Sinha e Wany Sampaio. Dele participaram muitos indígenas: crianças, mulheres, jovens, adultos. Os dados aqui apresentados foram retirados de Sampaio e Anastassioy (2006).
} 
linguísticas; nosso objetivo, na época, era estimular construções metafóricas espaço-temporais em Amondáwa.

Entre o corpus obtido, encontram-se muitas ocorrências de construções metafóricas ontológicas de personificação. Aqui, apresentamos apenas alguns exemplos que nos permitem propor como hipótese a metáfora conceitual de que "A casa é uma entidade/ um corpo", como em:

(5) Inambutinguhua apyryrym awowo tapyia tombeakaty apytawo

$\begin{array}{lllll}\text { Inambutinguhu-a } & \text { a-pyryrym } & \text { awowo } & \text { t-apyi-a } & \text { tombe-a-katy } \\ \text { galinha-NOM } & \text { 3s-rodear } & \text { ir-GER } & \text { rel-casa-NOM } & \text { costela-NOM-junto }\end{array}$

a-pyta-wo

3s-parar-GER

A galinha foi rodeando e parou ao lado da casa (na costela da casa)

(6) Inambutinguhua awata awowo tapyia apyryrym itombeare

$\begin{array}{lllll}\text { Inambutinguhu-a } & \text { a-wata } & \text { awo-wo } & \text { t-apyi-a } & \text { a-pyryrym } \\ \text { galinha-NOM } & \text { 3s-andar } & \text { ir-GER } & \text { REL-casa-NOM } & \text { 3s-rodear }\end{array}$

tombe-a-re

costela-nom-para/por

A galinha foi andando para perto da casa, rodeou pelo lado da casa

(7) Awata jam ua tapyia ikupekaty

a-wata jam u-a t-apyi-a kupe-katy

3s-andar novamente vir-GER REL-casa-NOM costas-junto

(a galinha) andou novamente e veio para trás da casa e ficou em pé atrás

(nas costas da casa).

(8) Awewe awowo tapyia pyriapa ikupekaty

a-wewe awo-wo t-apyi-a pyri ap-a i-kupe-katy

3s-voar ir-GER REL-casa-NOM perto ficar em pé-GER 3s. POS-costas-junto (a galinha) foi voando para perto, ficou em pé atrás da casa (junto da costas da casa)

Nos exemplos acima, encontramos ocorrências de personificação por meio de um processo conhecido como catacrese. Segundo Dubois et al. (1993:101), a catacrese é um "processo que consiste em ampliar o sentido de uma palavra para além do seu domínio estrito. A catacrese é uma metáfora cujo uso é tão corrente que não é mais sentida como tal (ex.: o pé da mesa, o braço da cadeira, a asa do moinho, etc.)." 
Vimos que à casa são atribuídas características do domínio, senão especificamente humano, dos seres animados, que podem possuir costas e costelas. Nos exemplos (5) e (6), a casa possui costelas e nos exemplos (7) e (8) a casa possui costas.

Em Amondáwa as palavras kupea (costas, parte posterior do corpo) e tombea (costela) são utilizadas com um pronome possessivo, marcador de posse humana inalienável, cujo genérico é ae; (aekupea - costas da pessoa; aetombea - costela da pessoa); os prefixos pronominais marcadores de posse humana inalienável são: $j i$ (1s); nde (2s) ga/hea/i (3s); nãnde (1pl inclusivo); oro/ore (1 pl exclusivo); pe (2pl); ngã (3pl). Quando se trata de possuidor não humano, geralmente é usado o nome do possuidor antes do objeto possuído (tapyiakupea - costas da casa; tapyiatombea - costela da casa).

A palavra kupea é também utilizada como um posicional, para indicar localização de posterioridade de pessoas, animais, objetos, etc. em relação a pessoas; neste caso, geralmente é usada em composição com o locativo katy (junto de) - como ocorre em (7) e (8), em que a casa está personificada muito embora o léxico Amondáwa disponha de outros vocábulos para indicar localização de posterioridade, como por exemplo, a palavra -ewir- (atrás).

Para indicar a posição lateral, encontramos a palavra -awai- (ao lado), que pode ser utilizada para indicar a localização de pessoas, coisas, animais com relação a pessoas, coisas, animais. Geralmente é utilizada com um prefixo relacional $\mathrm{r}$ - (que se refere ao objeto, pessoa ou coisa que é o referente da localização) em composição com o locativo katy ( $r$-awai-katy = ao lado de, junto de). Vê-se que as construções (5) e (6) aqui mostradas não utilizaram tal recurso lexical para evidenciar a lateralidade, preferindo utilizar a personificação da casa, atribuindo-lhe características de um corpo animado possuidor de costelas.

Culturalmente, a casa figura como uma referência espacial extremamente importante para os povos do mundo; para os Amondáwa, parece que a casa não é tão somente um local para morar, mas é um corpo que tem vida. Tradicionalmente, a casa Amondáwa abrigava não somente a ânime dos vivos, mas também as almas dos mortos, que eram enterrados sob as fogueiras que aqueciam cada família nuclear. No interior da casa comemorava-se o nascimento de uma nova vida e pranteavam-se os mortos, guardando-se na casa suas almas para que não se transformassem em anhangas, espíritos perdidos, assombrações... Talvez essa funcionalidade quase sagrada de guardar a vida e a morte seja uma motivação fundamental para a metáfora conceitual que personifica/humaniza a casa na cultura e na língua Amondáwa.

\subsection{Palavras compostas}

Tradicionalmente se diz que as palavras de uma língua podem ser estruturadas pelos processos de derivação e composição. 
A nominação por derivação geralmente acontece por mudança de categoria da palavra, caso em que o acréscimo ou a redução de sufixos podem alterar o significado básico da palavra, mas não a sua referência, como, por exemplo, no português, dizemos que "marcação" é um nome derivado do verbo "marcar"; "canto" é um nome derivado do verbo "cantar"; nesses casos, a alteração sufixal (seja por acréscimo ou redução), alterando o conteúdo semântico da palavrabase, transporta este conteúdo semântico para uma outra categoria de palavras (verbo $>$ nome). Além disso, a derivação por sufixação pode acrescentar um (ou mais) traços semânticos à palavra-base, atribuindo-lhe um novo aspecto, como em "casinha", "casona", não alterando a categoria da palavra em ambos os casos (mudança de categoria e acréscimo de traço semântico).

Na nominação por composição, "cuja função principal é a nomeação ou caracterização dos seres, o acréscimo semântico ocorre em grau máximo, provocando o desvio, às vezes total, da referência inicial para uma nova, realizando, assim, sua função de nomeação" (Silva 2011:29). Como exemplos do português, temos palavras compostas como: guarda-roupa, beija-flor, portabandeira, etc.

Considerando que a metáfora desempenha um papel extremamente importante na criação lexical, analisamos, ainda que preliminarmente, algumas palavras compostas da língua Amondáwa; na composição dessas palavras, encontramos ocorrências de processos metafóricos que envolvem a personificação e outras metáforas ontológicas. Consideramos apenas palavras formadas pelo processo de composição e que se constituam como nomeações metafóricas em que o objeto é denominado em razão de propriedades a ele transferidas por associação (cf. Basílio 2007).

Exemplos de metáforas figurativas (por personificação)

(9) Yvapoa $=$ raiz

yva po a

árvore mão NOM

"mão da árvore"

(10) Ojurua (okajurua) $=$ porta

o(ka) juru a

casa boca NOM

"boca da casa"

(11) Kwarendya = sereno

kwara endy a

sol cuspe/saliva NOM

"cuspe/saliva do sol" 
(12) Kwarahyanga = sombra kwarahy ang a

Luz do sol fantasma NOM "fantasma do sol"

Nos exemplos de (9) a (12) encontramos construções metafóricas de personificação por meio de catacrese: raiz (mão da árvore); porta (boca da casa); sereno (cuspe/saliva do sol); sombra (fantasma do sol).

Exemplos de metáforas descritivas

(14) Pirakweranga $=$ sereia

pira kwer ang a

peixe passado fantasma NOM

"fantasma (que) já foi peixe"

(15) Jatata'ia (Jahytata'ia)= estrela

jahy tata 'i a

lua fogo ASPEC (DIM.) NOM

"foguinho da lua"

(16) Jahyendykatua = lua (cheia)

jahy endy katu a

lua brilhar bonito NOM

"lua (que) brilha bonito"

(17) Tataxinga = fumaça

tata ting a

fogo branco NOM

"branco do fogo" (o branco que pertence ao fogo)

(18) Evirikuara = ânus

eviri kuar a

atrás buraco NOM

"buraco de trás"

(19) Akutinambia = cogumelo

akuti nambi a

cotia orelha NOM

"orelha de cotia (cogumelo em forma da orelha da cotia)" 
(20) Guararukara = taioba

guararu kar a

caranguejo batata NOM

"batata do caranguejo (batata que se assemelha ao caranguejo)"

Nos exemplos de (14) a (20) encontramos construções metafóricas descritivas: sereia (fantasma que já foi peixe); estrela (foguinho da lua); lua cheia (lua que brilha bonito); fumaça (branco do fogo/que pertence ao fogo); ânus (buraco de trás) cogumelo (orelha de cotia); taioba (batata-caranguejo).

Pode-se perceber, através dos exemplos dados (9 a 20), que a formação de palavras por composição, além de caracterizar processos metafóricos, sejam figurativos ou descritivos, revela diferentes tipos de estruturações, como: substantivo + substantivo $(9,10,11,12,19.20)$; substantivo + tempo + substantivo (14); substantivo + substantivo + aspecto (15); substantivo + verbo + adjetivo (16); substantivo + adjetivo (17); advérbio + substantivo (18), demonstrando uma riquíssima produtividade na nominação metafórica dos seres pelos falantes Amondáwa.

Estas diferentes possibilidades de estruturação de palavras em uma língua, segundo nosso grande mestre Aryon Dall'Igna Rodrigues (1986:27),

[...] revelam também distintas maneiras de focalizar certos aspectos ou certas propriedades dos objetos ou das situações que envolvem os falantes de uma língua, seja ela indígena ou não. E permitem ver que cada língua tem determinadas finezas de expressão, que podem coincidir parcialmente com o que se dá em outras línguas, mas que, no conjunto, caracterizam uma língua dada como um sistema único de expressão humana, no qual se cristalizam os efeitos de uma experiência de vida e de análise inteligente do mundo acumulada através de inúmeras gerações de um povo. Cada língua indígena brasileira não só reflete, assim, aspectos importantes da visão de mundo do povo que a fala, mas constitui, além disso, a única porta de acesso ao conhecimento pleno dessa visão de mundo que só nela é expressa.

\section{Conclusão}

Neste trabalho, analisamos textos narrativos, sentenças complexas e palavras compostas da língua Amondáwa, buscando melhor compreender construções metafóricas ontológicas em línguas Tupí, com base na teoria cognitiva da metáfora. Para tanto, buscamos perceber, na língua cotidiana dos falantes Amondáwa, as relações que estes falantes fazem entre a sua experiência do domínio físico, a natureza conceptual do pensamento e a arquitetura da linguagem. 
Vimos que, no reconto do mito "a origem da lua", através do jogo de sequências de imagens, as crianças narradoras realizaram construções metafóricas ontológicas por meio da personificação, atribuindo características de humanidade e/ou animacidade a seres como a lua, a noite e as estrelas; a personificação da lua e das estrelas pode ser suportada por uma metáfora conceitual "Corpos celestes são pessoas"; a personificação da noite pode ser suportada por uma metáfora conceitual do tipo "Tempo é movimento".

$\mathrm{Na}$ análise de sentenças complexas foram encontradas ocorrências de construções metafóricas ontológicas de personificação da casa à qual se atribuem características de humanidade e/ou animacidade como as de possuir costas e costela; tais construções podem ser suportadas por uma metáfora conceitual do tipo "A casa é uma entidade/um corpo".

Com referência à analise de palavras formadas por composição, encontramos diversos exemplos de nominações metafóricas ontológicas, seja por processos metafóricos figurativos - como a personificação por meio de catacrese-, seja por processos metafóricos descritivos - descrevendo os seres por suas características objetivas, de acordo com a visão de mundo do falante- revelando riquíssima produtividade na nominação metafórica dos seres pelos falantes Amondáwa.

Salientamos que os resultados aqui apesentados, enquanto estudos preliminares, estão sujeitos a erros, enganos, equívocos... Portanto, estamos abertos a críticas e contribuições.

\section{Referências}

Basílio, Margarida. 2007. Teoria Lexical. São Paulo: Ática.

Benjamin, W. 1985. O narrador: considerações sobre a obra de Nikolai Leskov. In Magia Técnica, Arte e Política. São Paulo: Brasiliense.

Croft, W.; D. A. Cruse. 2004. Cognitive linguistics. Cambridge: Cambridge University Press.

Dubois, J. et al. Dicionário de Linguística. São Paulo: Cultrix, 1993.

Lakoff, G.; M. Johnson. 2002. Metáforas da vida cotidiana. Campinas, SP: Mercado de Letras; Educ. (Coleção As Faces da Linguística Aplicada)

Lakoff, G. 1987. Women, fire and dangerous things: what categories reveal about the mind. Chicago: University of Chicago Press.

Kövecses, Z. 2005. Metaphor in culture: universality and variation. Cambridge: Cambridge University Press.

2006. Language, culture and mind: a pratical introduction. Oxford: Oxford University Press.

2009. Metaphor, culture and discourse: the pressure of coherence. In: A. Mulsolff \& J. Zinken (Eds.). Metaphor and discourse. London: Palgrave Macmillan, pp. 11-240. 